\section{P-7 STARTING THE CONVERSATION - INTEGRATING A DEATH CAFÈ INTO THE UNDERGRADUATE NURSE CURRICULUM}

${ }^{1}$ Kerry Blankley, ${ }^{2}$ Deborah Dowsett. 'LOROS Hospice, Leicester, UK; ${ }^{2}$ De Montfort University, Leicester, UK

\subsection{6/bmjspcare-2019-HUKNC.31}

Background Student nurses often feel unprepared to care for and communicate with dying patients and have particular fears and anxieties before their first placement (Cavaye \& Watts, 2014; Poultney, Berridge, Malkin, 2014). Educators need to help nurses recognise and confront their own reactions to death and to prepare nurses for this experience (Henoch, Melin-Johansson, Bergh, Strang et al., 2017; Dickinson, Clark \& Squire, 2008).

Aims To allow opportunities for student nurses to discuss their beliefs and attitudes to death and dying and to voice their fears, anxieties and positive thoughts about caring for people who are dying.

Methods All first year adult nurses in 2018-19 attended a 2 hour interactive workshop in groups of $30-40$ with two facilitators. Students were advised of the content in advance to allow discussion of personal issues which might require the student to opt out. Students were asked to discuss words which came to mind when thinking about death and dying, what might be important to them if they were dying and their anxieties and any positive thoughts about caring for dying people. One cohort (30 students) were asked to identify key learning.

Results $100 \%$ of students reported the session was useful and specifically identified the interactive approach as helpful in facilitating learning and managing the emotional subject matter. Students identified key learning points as: feeling more confident in what to expect when caring for the dying; importance of communication and talking about death; empathy; realisation that other students have similar worries; and identifying where to get support. Five (17\%) students reported that the session would have been better shorter as it was emotional.

Conclusion Evaluation of a pilot workshop for undergraduate student nurses has demonstrated positive learning. A substantial minority find this learning has a high emotional impact. This pilot is the first step in examining students' perceptions and anxieties about caring for dying people and integrating educational support within the undergraduate curriculum.

\section{P-8 DEAD CHATTY!}

Louise Johnson, Paul Marriott. St Cuthbert's Hospice, Durham, UK

\subsection{6/bmjspcare-2019-HUKNC.32}

Background Research suggests that young people are much less comfortable than their older counterparts with the topic of dying and death in a variety of different ways (Dying Matters Coalition, 2016). Engagement with the local college identified a gap in talking to young people about death, particularly in the context of students responsible for having 'good death conversations' within their chosen profession.
Aims To create/facilitate the development of a safe space for students of health and social care and those going into public services, to explore the subject of death and how to have difficult conversations. The dialogue may be different for each group, but how you feel when talking to families may be similar.

Methods Pilot project launched April - June 2019, $1 \times 2$ hours per month, non-compulsory, with coffee and cake (mandatory). Course tutors attended and college counsellors notified in case further support required. Sessions were student led but focussed on key topics, and they chose the project name 'Dead Chatty', as it reflected the open nature of the discussions.

Results of evaluation 28 students; attended up to three sessions - 12 evaluated.

Distance travelled calculation based on questionnaire, shown as percentage improvement.

(No change $=3$ ); $0 \%-9 \%=2 ; 10 \%-19 \%=2 ; 20 \%-29 \%=4$; $30 \%-39 \%=1$

Conclusions It was difficult to get students together (short project, exam times, work placements etc.) better scheduling might help, as would running over the whole academic year. There were tangible changes within the group on the subject matter, confidence grew and humour developed.

What did you like best?

- People sharing experiences

- Open discussions

- No judgement of opinions.

What could be improved?

- Nothing

- More sessions.

A space where students can ask questions, be supported and tackle the taboo of death and dying has been created.

\section{P-9 CHALLENGING CONVERSATIONS: TRAINING VOLUNTEERS TO SUPPORT THE ELDERLY AROUND END OF LIFE ISSUES}

Rebecca Turner. St Christopher's Hospice, London

\subsection{6/bmjspcare-2019-HUKNC.33}

Background St Christopher's is increasingly working with local voluntary organisations which support those who are elderly and frail to improve confidence with regards to end of life. Our patient support volunteers are regularly part of conversations around end of life and are honing sophisticated communication skills about subjects many find challenging.

Aims

- To develop the skills of St Christopher's volunteers to provide training for others as a less 'formal' face of hospice care;

- To increase the confidence and skills of local volunteers who support elderly, frail, and vulnerable people in speaking about death;

- To ensure sustainability by increasing the capability of other organisations to develop the skills and expertise of their own volunteers;

- To support better health outcomes at end of life. 
Method Connected with two local partner organisations. Recruited six existing volunteers and co-produced a three-hour training course entitled 'Challenging Conversations'. Our volunteers delivered a train the trainer course to staff and volunteers from our partner organisations who then delivered the training to their own volunteers. Evaluation was run alongside this project.

Results A comprehensive training resource has been produced for our partner organisations. Ten staff members and eight volunteers from our partner organisations were trained in how to successfully deliver the course. $94 \%$ of the delegates said they felt confident in delivering the course to others. 62 partner organisation volunteers are in the process of being trained. Our aspiration is that around 200 of our partner service users will be enabled to influence the care they receive at the end of life.

Conclusions This is a sustainable way for St Christopher's to extend its reach into the community to deliver an appropriate education intervention for those giving time in other organisations.

Acknowledgments With thanks to the Heath Innovation Network (HIN) for funding this work. And to our partner organisations Entelechy Arts and Age UK Bromley and Greenwich.

\section{P-10 TESTING REAL TALK: AN ADAPTABLE EVIDENCE-BASED COMMUNICATION SKILLS INTERVENTION IN END OF LIFE TALK}

${ }^{1}$ Sharan Watson, ${ }^{2}$ Becky Whittaker, ${ }^{2}$ Ruth Parry. ${ }^{1}$ University of Derby, Derby, UK; ${ }^{2}$ Loughborough University, Leicestershire, UK

\subsection{6/bmjspcare-2019-HUKNC.34}

Background Gaps in practice knowledge exist in initiating and navigating through difficult conversations; these new resources provide impactful, evidenced based learning opportunities in developing competence/confidence in engaging patients in end of life talk. Analysis of filmed data of patient consultations at a UK hospice provides the materials for 'Real Talk'; a novel and flexible education intervention containing real-life video clips. Communication skills training is more likely to be effective in changing behaviours when it is experiential and interactive, being relevant to trainees' practice.

Aim Real Talk interventions were tested out to determine ongoing development of communication skills training for the health and social care workforce.

Methods Experienced palliative care doctors attended a threeday facilitated residential workshop in which they explored the Real Talk. Discussions linked to the evidence of communication strategies, reflective diaries and action planning provided opportunity for linking learning to their clinical and educator roles.

Results 29 experienced palliative care doctors attended the workshop who completed a pre/post questionnaire (adapted from a validated tool) and reflective diaries. Delegates identified the most effective aspects of learning as: experiential small group work relating to Real Talk video clips, critiquing underpinning evidence of how clinicians navigate conversations in end of life care and the opportunity to reflect on learning and application to practice in a safe and stimulating environment.
Conclusions Engagement and results of the workshop have provided a foundation on which to build flexible communication skills training beyond the hospice setting, in engaging patients in end of life talk. Providing interactive experiential learning, embedded in the evidence base underpinning Real Talk, is crucial for health and social care professionals to develop skills in communicating with patients facing the end of life. The launch of the online Real Talk resources is now recommending that this adaptable approach be skilfully facilitated in safe environments for enhancing skilled practice in end of life care.

\section{P-11 SUPPORTING OLDER PEOPLE IN PALLIATIVE CARE WITH ORAL HISTORY}

${ }^{1}$ Michelle Winslow, ${ }^{1}$ Sam Smith, ${ }^{2}$ Richard Cave, ${ }^{3}$ Valerie Harrington, ${ }^{4}$ Arlene Honeyman, ${ }^{5}$ Catherine Mather, ${ }^{6}$ Sharon O'Donnell, ${ }^{7}$ Clare Williams. 'School of Nursing and Midwifery, University of Sheffield, Sheffield, UK; ${ }^{2}$ St Luke's Cheshire Hospice, Winsford, UK; ${ }^{3}$ Macmillan Solutions, Northmoor Community Centre, Manchester, UK; ${ }^{4}$ Ashgate Hospicecare, Chesterfield, UK; ${ }^{5}$ Palliative Care, North Tyneside General Hospital, North Shields, UK ${ }^{6}$ Macmillan Unit, Northern Health and Social Care Trust, Antrim Area Hospital, Antrim, UK ${ }^{7}$ St Luke's Hospice, Sheffield, UK

\subsection{6/bmjspcare-2019-HUKNC.35}

The UK population is living longer. By 2030 one in five people will be aged 65 or over, with the $85+$ age group the fastest growing (Office for National Statistics, 2018). A larger older population means more people developing conditions in later life appropriate for palliative care. However, there is limited understanding of this older group's end-oflife care needs, which include psychosocial issues of loss of meaning, wellbeing and dignity (Stow, Spiers, Matthews, Hanratty et al., 2019). Oral history is a biographical approach that captures personal experience, it complements and enhances palliative care by offering opportunities to audio record memories and have them permanently archived. Oral history is an opportunity to reinforce identity, acknowledge achievement, reflect on challenges and enhance self-esteem.

The first UK oral history project in palliative care began in 2007 in the Sheffield Macmillan Unit for Palliative Care, followed by six further projects in England and Northern Ireland. Team members are staff and volunteers who are trained and supported in oral history methods and ethical practice. This presentation will reflect on experience from these projects, discuss best practice in the context of adding value to care, consider the patient's expert role regarding their own interests and draw on research in partnership with Macmillan Cancer Support.

Key findings are that oral histories recorded with an empathetic, non-judgemental listener, with no time limit or medical agenda, enables expression of earlier life identities that can be cathartic, validating and dignified. Bereaved family and friends highlight that an important aspect of oral history is receiving a voice recording as a lasting memory.

The oral history process can be as beneficial and important as the oral history outcome. Oral history projects can add an additional positive dimension to the care of older people in palliative care through in-depth and meaningful interaction between project teams, participants and family. 